\section{Protein C Deficiency and Acute Myocardial Infarction in the Third Decade}

Steven M. Hacker, MD, Brian D. Williamson, MD, Steven Lisco, MD, James Kure, MD, Michael Shea, MD, and Bertram Pitt, MD

$\mathbf{P}$ rotein $\mathrm{C}$ deficiency has been associated with a predisposition to venous thrombosis and thromboembolism. Arterial thrombosis has been seen much less frequently and may require other vascular risk factors. Here we describe a young patient with protein $\mathrm{C}$ deficiency presenting with an acute myocardial infarction (AMI).

A 28-year-old white man, with a history of cardiac contusion, was transferred on June 22, 1990 for further management after an AMI. On March 24, 1989, 15 months before his AMI, the patient sustained a myocardial contusion from a motor vehicle accident. This was manifested by a transient right bundle branch block, which appeared to have resolved on subsequent electrocardiograms. After this episode he was asymptomatic until June 19, 1990, when he developed substernal chest pressure radiating to the left shoulder, with diaphoresis, nausea and vomiting. Electrocardiogram revealed $Q$ waves in leads $I$ and $a V L$, and 2 mm ST elevation in leads $I, a V L$, and $V_{3}$ to $V_{6}$. Eight hours after the onset of pain he received recombinant tissue-type plasminogen activator intravenously. The pain persisted and he underwent emergency cardiac catheterization, which revealed a thrombus in the left main coronary artery, a large normal right coronary artery, and a small normal left circumflex coronary artery. Intracoronary recombinant

From the Division of Cardiology, University of Michigan Medical Center, Ann Arbor, Michigan 48105. Manuscript received October 18, 1990 ; revised manuscript received and accepted February 25, 1991. tissue-type plasminogen activator and systemic streptokinase were given. Creatine phosphokinase peaked at 4,200 IU. He was administered nitroglycerin, full-dose heparin and lidocaine, and was transferred to our hospital.

As a child he had asthma. He was receiving no medications at the time of presentation. There was a 15 pack-year history of cigarette use but he had not smoked in the preceding 2 years. He worked as a machine operator and denied alcohol or drug abuse. His family history was remarkable for a father with protein $C$ deficiency based on a history of recurrent thromboembolism and a protein $C$ activity of 47\%. His paternal uncle died from AMI at age 35 years. Two followup cardiac catheterizations revealed a marked decrease in the size of the left main thrombus, with apical akinesia and otherwise normal myocardial wall motion. He was discharged while receiving warfarin, atenolol and aspirin. His first protein $C$ antigen level $o b$ tained while he was in the hospital and receiving heparin was depressed at $51 \%$ (normal 70 to $130 \%$, Southeastern Wisconsin Hemostasis Laboratory). The total protein $S$ was normal at $90 \%$, whereas the free protein $S$ was slightly depressed at $63 \%$. The factor $X$ was normal at $76 \%$. The protein $C$ antigen level was repeated 4 weeks later and remained depressed at 54\%. The antithrombin III level was normal at $95 \%$ (normal 86 to 140\%). His total cholesterol was $167 \mathrm{mg} / \mathrm{dl}$, triglyceride level $129 \mathrm{mg} / \mathrm{dl}$, high-density lipoprotein $44 \mathrm{mg} / \mathrm{dl}$ and low-density lipoprotein $102 \mathrm{mg} / \mathrm{dl}$. During the hospitalization his hemoglobin was $13.9 \mathrm{~g} / \mathrm{dl}$, hematocrit was $40 \%$, and platelet count varied from 200,000 to 494,000 per $\mu l$ (normal 200,000 to $400,000 / \mu l$ ). There was no evidence of liver disease or vitamin $K$ deficiency, as the transaminases were normal, albumin was $4.5 \mathrm{~g} / \mathrm{dl}$, and coagulation studies revealed a prothrombin time of 12.4 seconds and a partial thromboplastin time of 27.4 seconds. His fibrinogen was $311 \mathrm{mg} / \mathrm{dl}$ and $\mathrm{fi}-$ brin split products were $<8 \mu \mathrm{g} / \mathrm{ml}$. The Westergren sedimentation rate was normal at $12 \mathrm{~mm} / \mathrm{hour}$.

Protein $\mathrm{C}$ deficiency is a hereditary disorder transmitted in a codominant fashion. Heterozygous persons have $<60 \%$ of normal plasma levels of protein $\mathrm{C}$, whereas homozygous persons have no detectable levels of protein $\mathrm{C}$. The homozygous state usually presents in the neonatal period as a devastating disease called purpura fulminans neonatalis. The heterozygous state generally comes to clinical attention in the late teens or early twenties, manifested as superficial thrombotic episodes, deep venous thrombosis, pulmonary embolus or, less frequently, arterial thrombosis.

The anticoagulant protcin $\mathrm{C}$ and its cofactor, protein $\mathrm{S}$, require vita$\min \mathrm{K}$ for the post-translational step that adds a $\gamma$-carboxyl group to glutamic acid residues. This step occurs in the liver and is inhibited by warfarin. Procoagulant factors such as II, VII, IX and X also must undergo this carboxylation to function as procoagulants. Except for protein S, all of the vitamin $\mathrm{K}$-dependent proteins circulate as zymogens that must be cleaved to form active serum proteases. Protein $\mathrm{C}$ is activated by an interaction between thrombin and thrombomodulin at the surface of the endothelial cell. Thrombomodulin is an intrinsic membrane protein 
of the endothelial cell. When thrombin binds to thrombomodulin, protein $C$ is cleaved and activated much more readily than in the circulation. The majority of activation occurs in the capillary beds, where the proportion of endothelial cell surface (and therefore thrombomodulin) to circulating blood volume is high. Activated protein $\mathrm{C}$ acts as an anticoagulant by cleaving and inactivating factors $\mathrm{V}$ and VIII, which normally serve to promote the activity of factor $\mathrm{Xa}$ and IXa, respectively. Activated protein $C$ has also becn shown to increase the activity of the fibrinolytic system. Protein $\mathrm{C}$ therefore represents a mechanism for the endothelial cell surface to maintain a hemostatic balance, and deficiency of the factor would create an increased tendency for thrombosis.

Protein $\mathrm{C}$ deficiency is well known to be associated with thromboembolic disease. ${ }^{1}$ Although most reported cases of thromboses have occurred in the venous system, arterial thrombosis has occurred on occasion. ${ }^{2}$ Coller et al $^{3}$ described a 28 year-old man with protein $C$ deficiency and a smoking history who had recurrent deep venous thromboses, pulmonary embolism and AMI. Cardiac catheterization at the time of AMI revealed a thrombus occlud- ing the left anterior descending coronary artery, without coronary atherosclerosis. This patient had coronary artery bypass surgery and was discharged while receiving warfarin. The patient later discontinued warfarin on his own and developed left radial and ulnar artery occlusions.

A report in 1987 estimated that 1 in 300 adults are heterozygous for protein $\mathrm{C}$ deficiency, although low protein $\mathrm{C}$ levels did not, by themselves, appear to explain an increased risk of thrombosis. ${ }^{4}$ It is likely that other factors in addition to protein $\mathrm{C}$ deficiency contribute to the development of thrombosis, such as damaged endothelium, vascular stasis, or other imbalances between procoagulants and anticoagulants. Therefore, any injury to the endothelial cells that affects proper expression of thrombomodulin, synthesis of protein $S$, or Va inactivation could potentially lead to a hypercoagulable state and thrombotic complications in the presence of a low protein $\mathrm{C}$ level.

The preceding cardiac contusion may have predisposed our patient to his AMI. Although the contusion occurred 15 months before the infarction, blunt chest trauma has been associated with late coronary artery stricture presenting 10 months lat- er. ${ }^{5}$ Cardiac contusion with delayed $\mathrm{AMI}$ in a protein C-deficient patient has never been reported.

It appears that this patient's protein $\mathrm{C}$ deficiency in the presence of other vascular risk factors (i.e., contusion, remote history of cigarette smoking and a family history of premature AMI) may predispose to early AMI. Furthermore, young patients with AMI and a family history suggestive of hypercoagulability should undergo hematologic evaluation, including a check of protein $\mathrm{C}$ levels. In patients diagnosed with protein $\mathrm{C}$ deficiency and a history of recurrent thrombocmbolism, warfarin would be the therapy of choice to prevent subsequent episodes of thrombosis.

1. Griffin JH, Evatt B, Zimmerman TS, Kleiss AJ, Wideman C. Deficiency of protein $\mathrm{C}$ in congenital thrombotic disease. J Clin Invest 1981;68: 1370-1373.

2. Conrad J, Samama MM. Inhibitors of coagulation, atherosclerosis, and arterial thrombosis. Sem Thromb Hemost 1986:1 2:87-90.

3. Coller BS, Owen J, Jesty J, Horowitz D, Reitman MJ, Spear J, Yeh T, Comp PC. Deficiency of plasma protein $\mathrm{S}$, protein $\mathrm{C}$, or antithrombin $\mathrm{III}$ and arterial thrombosis. Arteriosclerosis 1987;7:456-462.

4. Miletich J, Sherman L, Broze G Jr. Absence of thrombosis in subjects with heterozygous protein C deficiency. N Engl J Med 1987;317:991-996.

5. Wainwright RJ, Edwards AC, Maisey MN, Sowton E. Early occlusion and late stricture of normal coronary arteries following blunt chest trauma. Chest 1980;78:796-798.

\section{Upright Retrograde P Waves During Ventricular Tachycardia}

Ray Parkin, MB, BS, George Nikolic, MB, BS, and

David H. Spodick, MD, DSc

$\mathrm{T}$ he morphology and axis of retrograde atrial activation have been well defined: a

From the Intensive Care Unit, Woden Valley Hospital, Australia, and the Cardiology Division, St. Vincent Hospital, University of Massachusetts Medical School, 25 Winthrop Street, Worcester, Massachusetts 01604. Manuscript received December 6, 1990; revised manuscript received and accepted February 19,1991 . negative deflection in leads II, III and aVF, reflecting a frontal plane axis of -31 to -100 degrees ${ }^{1,2}$ Retrograde $P$ waves upright in the same leads are well documented ${ }^{3}$ but exceedingly rare in clinical electrocardiography. When observed in association with broad ventricular complexes, they can be mistaken for upright $P$ waves of sinoatrial initia- tion and can be responsible for resulting misdiagnoses. ${ }^{4}$ An example of ventricular tachycardia with positive yet undoubtedly retrograde $P$ waves is described below.

The pationt, a 63-year-old man, had prolonged weakness and lightheadedness at rest with diaphoresis, dizziness and blurred vision, but no chest pain. These symptoms recurred in a milder form 9 years after a myocardial infarction. Electrocardiography revealed ventricular bigeminy with occasional runs of ventricular tachycardia. He was given lido- 